\title{
FRANCIS PONGE O EL LIRISMO DE LO BANAL
}

\author{
Elena Suárez Sánchez
}

\begin{abstract}
Francis Ponge is a difficult writer to clasify within French Literature because he is an isolated author and rebel against the traditional poetic forms. His work is a sensual approach to the world of trivial objects. Essentially, his poetic production aims to free matter from its inert condition, giving it a particular sense of life. Ponge thus become a spokesman for simple things by using a language of concision and exactness. His starting point is a wide repertory that takes in objects, animals, atmospheric phenomena and landscapes. He establishes analogies between them and the human being which leads to allegory. His poetry, without the burden of emotions or amorous exaltation, intends to represent the balance betweenthe external world and its literary expression based on an artistic definition of simple things.
\end{abstract}

Dentro de las pretensiones de Francis Ponge no figuró nunca la de ser considerado poeta. Su actitud algo más que reticente a verse incluido en la tradición poética lo convierte en un escritor difícil de clasificar ya en su época dentro de la literatura francesa ${ }^{1}$. Lo sigue siendo hoy, ocho años después de su muerte. Sin antepasados literarios que puedan justificar la inspiración total de su obra, sin discípulos que supieran, no cayendo en la simple imitación, ir más allá, resulta ser un escritor aislado, sorprendente en su -valga el oxímoron- complicada sencillez. El propósito de mi análisis es subrayar las líneas de fuerza de su obra y mostrar la jerarquía de los motivos que en ésta se tratan para arriesgar finalmente una definición de quien llegó a ser experto en ella.

En su deseo de aportar una respuesta coherente a los interrogantes que plantea para todo artista la relación hombre-mundo, Ponge recorrerá un itinerario espiritual y poético lleno de sinuosidades. Empieza a escribir desde un sentimiento de insatisfacción con respecto a las condiciones naturales que el mundo impone al hombre, y a los condicionamientos socioeconómicos que éste es capaz de imponer a sus iguales.

A Ponge nunca llegará a gustarle la organización de la existencia humana tal como está establecida. Esa desaprobación lo llevará a rebelarse puntualmente, a denunciar la injusticia social, a la desesperación ocasional, a buscar refugio, como ya habían hecho otros antes que él, en los valores artísticos. La literatura, que representará en muchos momentos para él un espacio

\footnotetext{
${ }^{1}$ En repetidas ocasiones (La Rage de l'expression, Méthodes) ha rechazado la calidad de poeta de manera drástica: "Le jour où l'on voudra bien admettre comme sincère et vraie la déclaration que je fais à tout bout de champ que je ne me veux pas poète, que j'utilise le magma poétique, mais pour m'en débarrasser, que je tends plutôt à la conviction qu'aux charmes, qu'il s'agit pour moi d'aboutir à des formules claires et impersonnelles, on me fera plaisir" F. Ponge, Méthodes, (1961) 41-42.
} 
sereno y protector, perderá sin embargo en otras ocasiones los tintes de vía de salvación. Vendrá entonces una reacción de desengaño que hará al escritor parodiar con acritud la escritura como tal, llegando incluso a no ver más solución que optar por el silencio literario.

Si bien no son sorprendentes las denuncias de las dificultades cotidianas que plantea la sociedad a un joven sin demasiados recursos económicos como era su caso, la actitud que adopta Francis Ponge frente al lenguaje sí puede resultar peculiar por su visceralidad. El lenguaje llega a repugnarle al convertirse en el representante del mundo corrompido que él no acierta a cambiar. El lenguaje que se utiliza en la vida corriente no puede dejar de estar comprometido con el engranaje de la producción y el sistema económico que lo sustentan. Es la utilización forzosamente colectiva del lenguaje lo que Ponge llega a aborrecer, la muerte de la expresividad individual ${ }^{2}$.

Sin embargo, no será capaz de abandonar la vía de la escritura. El mundo que lo rodea no cesa de procurarle estímulos, invitaciones de acercamiento que no sabe declinar. En un iluminado esfuerzo por sobreponerse a la pasividad decide lanzarse con furia contra el prosaísmo del lenguaje y analizar la realidad con ojos nuevos, lavados de convencionalismos y de tópicos con la ambiciosa pretensión de paliar el empobrecimiento progresivo a que sometemos las nociones de las cosas consideradas corrientes.

A partir de esa observación se propone formular de forma clara sus cualidades, combinando lo pintoresco y lo sorprendente. Este proyecto le permitirá reconciliarse con la vida al adoptar los presupuestos de la antigua sabiduría epicúrea, aceptando desde una melancolía que se pretende serena la inequívoca presencia de la materia, la esplendidez de la vida y la inexorabilidad de la muerte.

Dos serán para Ponge los modelos literarios dignos de tener especialmente en cuenta: Mallarmé y Lautréamont. El primero, por encontrar que la poesía exige una entrega total de sí mismo así como por querer insuflar al lenguaje una vida nueva; el segundo como promotor de una poesía impersonal al servicio de las potencialidades del lenguaje.

Sus motivos poéticos irán ganando progresivamente en accesibilidad y algunos de sus poemas en prosa se consagran a la evocación de realidades cotidianas tales como la meteorología, el ciclo de las estaciones o la modificación lumínica de un espacio. Ponge realiza asimismo el gran descubrimiento de los animales, de los objetos utilitarios. A partir de ese momento su propuesta poética será la de vivir la aventura de encontrar en lo insignificante la clave de lo sensacional.

Esta dirección parece haberse propiciado por la obligada convalescencia en Normandía de un accidente doméstico. La detenida observación de la naturaleza durante este periodo resucita en su mente el recuerdo infantil de un jardín de Avignon, ciudad en donde había residido de 1900 a 1909. No es ajeno tampoco a este cambio de rumbo el movimiento poético que impulsa a un grupo de jóvenes a recuperar valores que los surrealistas se habían encargado de desterrar.

\footnotetext{
2 "Hélas, pour comble d'horreur, à l'intérieur de nous-mêmes, le même ordre sordide parle, parce que nous n'avons pas à notre disposition d'autres mots ni d'autres grands mots (ou phrases, c'est-à-dire d'autres idées) que ceux qu'un usage journalier dans ce monde grossier depuis l'éternité prostitue". "Les écuries d'Augias" (1929-30), Proêmes (1948), 155156.
} 
Abandono a la libre inspiración, cándida mirada a lo inmediato, estimación de lo real frente a la surrealidad son los parámetros de poetas como Jean Follain o Eugène Guillevic, que Ponge va a compartir.

La energía inspiradora que da forma a su obra más representativa, Le parti pris des choses, no se agotará jamás alcanzando ya sea a textos cerrados -"textes-bombe" como él los llama por ser pequeños pero capaces de producir una explosión de sensaciones- o sobre textos mucho más largos como los de La Rage de l'expression, auténticos diarios de la práctica escritural, del propio acto textual que permite la aprehensión de un objeto o noción.

El sentido del título Le parti pris des choses es bastante explícito: Ponge se pone del lado de las cosas, en contra de la práctica humana de servirse egoístamente de los objetos ordinarios para desecharlos más tarde cuando ya no resultan útiles. Tomar partido por las cosas no significará sólo hablar de ellas, concederles la dignidad de convertirse en materia artística, sino constituirse en su portavoz. Para Ponge las cosas están condenadas al silencio. El cree oír su llamada, una especie de súplica que se siente obligado a interpretar. Si alguna superioridad tiene el ser humano sobre el resto de los demás seres es la facultad del lenguaje, tan innata, tan consustancial que Ponge la compara a una secreción inevitable, "la véritable sécrétion commune du mollusque homme" (Ponge 1942:77).

El sentido de la obra de Ponge es poner en marcha esa superioridad lingüística para liberar a la materia de su carácter inerte, reconocerle una vida particular, activa. Pero al mismo tiempo una interpenetración de los universos humano y objetual tiene lugar en su producción. No por ocuparse del mundo de los animales y las cosas, el de los hombres deja de ser el centro de su observación. El objeto es para Ponge un medio de expresión indirecta, pues su objetivo último es descubrir en la apariencia material de las cosas una dimensión alegórica, o dotarlas de ella deliberadamente en caso de que no la posean.

Esto explica que a menudo el texto traspase el umbral de la mera descripción e integre al objeto en una anécdota mediante una proyección de la subjetividad del autor y una antropomorfización de las cosas. Se observa entonces más que el respeto de la especificidad de cada forma de vida natural, una intención de otorgar a éstas la condición de lo humano. Para ello Ponge recurre con frecuencia a la reactivación de la catacresis, desandando el camino del sentido figurado hasta el sentido original de la palabra o expresión lexicalizada. Así en el poema dedicado a la naranja Ponge habla de "contenance" y de "expression" refiriéndose a la vez a la capacidad material y al dominio de sí en el primer caso y a exprimir el zumo y expresar una idea en el segundo: "il y a dans l'orange une aspiration à reprendre contenance après avoir subi l'épreuve de l'expression" (Ponge 1942:41). Igualmente afirma del caracol que posee una gran sangre fría. La araña por su parte es maestra de retórica pues no para de tejer el hilo de su discurso.

El aspecto de lo descrito suele evocar la fisiología humana: el vaso lleno de agua hasta rebosar parece morirse de risa mientras que el que está casi vacío llora por las gotas que parecen lágrimas ${ }^{3}$.

\footnotetext{
3 "Le verre d'eau en train de se remplir, qui se remplit trop, déborde, se renverse, se reremplit, en rit aux larmes: bouillonnant, débordant de générosité, de génie, de gaiété (...) Le verre d'eau qui vient d'être jeté (...) il s'en trouve tout couillon, appauvri, pleurant, pleurard, humide encore..." (Ponge 1961:160-161).
} 
El materialismo epicúreo de Ponge subyace en la contemplación de algunos motivos como si de naturalezas muertas se tratara, incidiendo especialmente en la acción inevitable del paso del tiempo: el otoño no es sino la descomposición de las hojas secas por efecto de la lluvia, la vida de la flor, una brillante agonía, el caracol vacío, un esqueleto tintineante. Los alimentos se presentan a menudo con alguna señal de descomposición o atacados, al ser ingeridos, por la química asesina de los jugos gástricos. Determinados objetos tienen un destino trágico, pues su razón de ser es languidecer hasta la destrucción: el jabón va muriendo convertido en espuma; la vela, después de haber servido fielmente al lector que la encendió "s'incline sur son assiette et se noie dans son aliment" (Ponge 1942:39); el cigarro arde en el fuego de su propia pasión: "Sa passion enfin: ce bouton embrasé, desquamant en pellicules argentées" (Ponge: 1942:40).

En De la nature morte et de Chardin (F. Ponge 1967) Ponge evoca la tradición de la naturaleza muerta, destacando aquella que toma como modelo un objeto intrascendente para transformarlo en símbolo de la fatalidad, del efecto aniquilador del tiempo. En sus poemas, bajo una apariencia humorística e inocente, Ponge nos recuerda a menudo la omnipresencia de la muerte, ante la cual se esfuerza por mantenerse indiferente, aceptándola como parte del ciclo natural. Las reflexiones de Ponge a propósito de las pinturas de Braque podrían igualmente ser aplicables al mensaje de sus textos: "Là seulement, nous pouvons voir comme dans le vide, se font et se défont les choses, comme elles naissent et meurent et renaissent autres, par la permutation de leurs éléments. Et ainsi voyons-nous le tout, où rien ne se crée jamais de rien" ${ }^{4}$.

El temperamento sensual de Ponge justifica el interés por el acercamiento físico a lo descrito, pero también hay que tener en cuenta su condición de investigador concienzudo. Cree Ponge que el artista debe doblemente -por ser hombre y tener el monopolio de la palabra y por ser artista- tomar a su cargo la función de corregir el mundo5. Más aún que el científico, aquél puede por su exacerbada sensibilidad derivar de sus consideraciones las leyes que rigen el mundo natural y justificar su orden; redefinir la esencia de cada cosa y darle a cada una el lugar conveniente como en la conclusión de una fábula. Es así como Ponge proyecta lograr su particular ataraxia, oponiendo a la angustia que la intuición del absurdo provoca en el hombre, la verdad tranquilizadora del objeto.

Ponge sabía que había dado con un campo original que le serviría para sorprender y para expresar su voluntad de ruptura con la poesía lírica tradicional. Una vez realizada su opción no dudará en desafiar si fuera preciso las nociones de buen gusto --describiendo la suciedad, la podredumbre- y de trascendencia pues elevará a la patata, al edredón, al plato, a la categoría de fuente inspiradora de un poema. La poesía sufre con él un violento desplazamiento hacia temas triviales, abandonando los caminos de la confidencia, el desengaño, la exaltación o la pasión amorosa. Esto supone un auténtico reto pues Ponge es consciente de que cuanto más banal es una cosa más espectacular debe resultar la capacidad del artista que sabe elevarla a pretexto poético.

\footnotetext{
${ }^{4} \mathrm{~F}$. Ponge, "Braque, un méditatif à l'oeuvre", L'Atelier contemporain (París 1977:313).

${ }^{5}$ En relación a esta alternativa, Ponge alude a la condición y cualidades del artista -en otras ocasiones habla de artesanovaliéndose de la comparación con un relojero: "La fonction de l'artiste est ainsi fort claire: il doit ouvrir un atelier, et y prendre en réparation le monde, par fragments comme il lui vient. Non pour autant qu'il se tienne pour un mage. Seulement un horloger. Réparateur attentif du homard ou du citron, de la cruche ou du compotier, tel est bien l'artiste moderne" F. Ponge, Méthodes (1961) 161.
} 
En cuanto al repertorio de objetos tratados, éste es bastante amplio. Puede tratarse de un paisaje panorámico como en La Seine, en donde a partir del elemento agua se evoca el curso entero del río; puede destacarse la evolución de la materia en el tiempo: Le Galet describe desde una perspectiva geológica a lo largo de miles de años, el paso de la roca a arena por la erosión: "Qu'on ne me reproche pas en cette matière de remonter plus loin même que le déluge" (Ponge 1942:92).

A los objetos naturales se añadirán más adelante los fabricados: la radio, el baño de zinc, la contraventana. Llegarán incluso a mezclarse ambos en un mismo texto por desmaterialización de lo real: el poema sobre el lagarto dedica los primeros párrafos al animal en movimiento para convertirlo por medio de su zigzagueo en un tren eléctrico.

Hay una preferencia por los objetos de pequeñas dimensiones, aquellos que caben en una mano. Esto autoriza la sensación de aprehensión total, de manipulación física. Con frecuencia se trata de objetos que se pueden comer, después de su despiece. La apertura material es imagen de entrada a un mundo secreto que guarda celosamente la auténtica esencia de las cosas.

Este viaje al interior de los objetos es propiciado por el cambio de escala a que se les somete. El lector de Notes pour un coquillage se siente empequeñecer hasta ver en la concha de un molusco "un énorme monument, en même temps colossal et précieux, quelque chose comme le temple d'Angkor, Saint-Maclou, ou les Pyramides, avec une signification beaucoup plus étrange que ces trop incontestables produits d'hommes" (Ponge 1942: 74). Igual ocurre con la corteza del pan vista como una cordillera o con la concha de la ostra que es firmamento de nácar. Mas no sólo se da en Ponge el paso de lo microscópico a lo macroscópico sino también el fenómeno inverso: el mundo estelar de las nebulosas es suscitado por la disposición de las bolas floridas de la mimosa ${ }^{6}$.

Se ha considerado con frecuencia que la flora y la fauna descritas por Ponge comprenden preferentemente las de la región mediterránea francesa: el caracol, la mariposa, la avispa, la rana, el lagarto, la mimosa, el clavel, la aceituna, el higo, el plátano, el espárrago, el albaricoque. Si bien es clara la presencia de la región de su infancia, habría que precisar no obstante que Ponge se muestra reacio a asumir las teorías de Taine y que pretende sobrepasar ese único espacio meridional. Las fronteras, ya sean intangibles o físicas, lo ahogan. Como afirma J.-M. Gleize: "Les origines sont enfouies, recouvertes. Mises au blanc, au silence. Une seule patrie, les mots et les choses. Le "buisson typographique" (Francis Ponge (1988:23).

Sea cual fuere el aspecto formal del texto pongiano consagrado a los objetos -limitado por su tema y su presentación en la página a una forma cerrada y concisa, o abierto y susceptible de ulteriores desarrollos y variaciones- su finalidad es siempre desgranar una serie de

\footnotetext{
${ }^{6}$ Jean Pierrot ve además en este cambio de escala una intención de ensoñación apocalíptica ya que en Le Mimosa Ponge presenta el nacimiento y la extinción de las estrellas que componen las nebulosas y compara la duración de la vida de aquéllas a la de la flor de la mimosa: "Chaque branche de mimosa est un perchoir à petits soleils intolérables, à petits enthousiasmes soudains (...) Comme dans un feu d'artifice réussi les fusées se terminent en éclatement de soleils" (Ponge 1976:92). La fragilidad de estas flores se une así a la fulgurante extinción que Ponge imprime a los soles numerosos de los que él habla cuestionando todo heliocentrismo. Se reflejaría así además que el estado actual de nuestro sistema solar por su enfriamiento general corresponde a una fase terminal. J.Pierrot, Francis Ponge (Paris 1993) 124.
} 
correspondencias, sin miedo a la excentricidad que puede provocar la asociación involuntaria, correspondencias que se condensan a menudo en una breve y brillante fórmula.

Los elementos retóricos de acercamiento que adopta Ponge parten de la analogía, procedimiento que por poner en contacto más que distintos elementos, distintas relaciones proporcionales, permite a Ponge describir un objeto o ser de un reino natural, empleando para ello términos que convendrían más a otro reino, siempre con vistas a producir una nueva impresión?. Así, el lagarto es punto de partida de una larga serie analógica de la que sólo citamos algunos elementos: "dragon chinois", "chef-d'oeuvre de la bijouterie préhistorique", "petit poignard", "petit bibelot ovipare", "petit train de pensées grises".

Del punto final de la analogía surge la metáfora proporcional que pone en juego cuatro términos: en el poema Le Papillon el polen -cuyo nombre se omite- es el azúcar del fondo de la flor por analogía explícita con el azúcar que queda en las tazas mal lavadas. Pero esta metáfora compleja no anula dentro del mismo texto la metáfora fundada únicamente sobre el parecido: la mariposa es "allumette volante", "petit voilier des airs". En otro poema de Le Parti pris des choses las imágenes "Sa feuille d'or tient impassible au creux d'une colonnette d'albâtre par un pédoncule très noir", se refieren a la vela.

La analogía desarrollada dará asimismo lugar a la alegoría, representación apreciada por Ponge, que ve en ella el disfraz necesario para la originalidad, al decir con ella algo distinto a lo que parece decirse.

El empleo sistemático de la polisemia le permite a Ponge multiplicar las relaciones entre las palabras; la paronimia favorece asimismo el deslizamiento escritural. El recurso a la etimología -real o fabricada por él mismo- provoca la sorpresa en el lector que debe hacer frente a un cierto culteranismo de la expresión: "formule", por ejemplo, significa forma pequeña al hablar de la perla en L'Huître.

Todo ello nos parece encaminado a la defensa de un particular conocimiento por el que lo que cuenta no es el objeto real, sino la noción mental que el escritor posee de él y más aún, su equivalente verbal. Las palabras y -como dice Ponge a Philippe Sollers (1970:169)- las fórmulas verbales le parecen una realidad concreta, tan evidente y tan palpable como el propio mundo exterior.

Una consecuencia que sacará Ponge de este espesor de lo verbal es precisamente la dificultad de metamorfosear lo real en palabra, habida cuenta que no hay entre los dos campos una relación científica. Aun admitiendo que objeto y poema son inconciliables, la irreprimible tendencia poética de Ponge le hará soñar con la confusión entre ambos. Por eso no acepta la arbitrariedad del signo lingüístico como axioma y se complace en imaginar que cada letra de una palabra guarda cierto parecido con el objeto que ésta designa, como si la lengua francesa tuviera un origen pictográfico. Así, en el término "oiseau" la S le sugiere el perfil de un pájaro

\footnotetext{
${ }^{7}$ En una emisión de la Cadena Nacional de Radiodifusión francesa, Ponge terciaba así sobre el tema en una conversación con Pierre Reverdy y André Breton: "Concernant l'analogie, je dirai que son rôle est important dans la mesure où une nouvelle image annule l'imagerie ancienne, fait sortir du manège et prendre la tangente. Rien n'est plus réjouissant que la constante insurrection des choses contre les images qu'on leur impose". Extrait des émissions Rencontres et témoignages dirigées par A. Parinaud, 1952.
} 
en reposo; la G de "gymnaste" indica que este deportista "porte le bouc et la moustache que rejoint presque une grosse mèche en accroche-coeur sur un front bas".

Yendo más allá de la simple etimología, crea la "généanalogie", y se reserva el derecho de acceder a las cuestiones de la paronomasia, de la etimología imaginada, de la contaminación verbal para reunir palabra y realidad. Nacen así "proèmes" (de "poèmes" y "prose"), "horizondelles" (de "horizon" e "hirondelles") y tantos otros neologismos. Esta actitud demiúrgica denota la nostalgia de un estado edénico de la lengua en que las características del objeto propiciaron el que el ser humano lo llamara de una determinada forma.

En conclusión, los textos de Ponge son algo más que una original y divertida enciclopedia. Más allá de la observación fenomenológica Ponge intenta construir un sistema completo del mundo, une metafísica basada en el positivismo moderno. Por medio de la observación de los objetos Ponge pone en marcha toda su visión personal del entorno, visión que llega a constituir una propuesta cosmológica a través de la poesía.

Parece evidente el deseo de este escritor de crear un subgénero a caballo entre la definición y la descripción de forma que pudieran asociarse la infalibilidad y brevedad de la primera con el respeto por el aspecto sensorial de la segunda.

Cerca y lejos de la ciencia a la vez -cerca por las cuestiones planteadas y la terminología empleada en ocasiones, lejos por las respuestas que ofrece- es por esa dicotomía por lo que Ponge es poeta a pesar suyo, al tomar partido por sí mismo y adoptar ante lo externo a él una actitud de alerta.

La poesía es para Francis Ponge el resultado de una doble sensibilidad: la que experimenta ante las cosas del mundo exterior y la que le hace vibrar ante ese otro mundo, el del lenguaje. El hallazgo de Ponge ha sido adecuar con acierto las dos sensibilidades, devolviendo a las palabras su vivacidad, su polivalencia desde el sentimiento de una cierta rabia, de un estremecimiento de la expresión por los que la pasión, en contra de lo previsto por él mismo, no está ausente de sus poemas finalmente. Lo que ocurre es que se ha sustituido el canto al amor por el himno a la palabra. 


\section{BIBLIOGRAFÍA}

Gleize, J.-M., Francis Ponge. Le Seuil, col. Les Contemporains, 1988.

Pierrot, J., Francis Ponge. París, José Corti, 1993.

Ponge, F., Le Parti pris des choses suivi de Proêmes. Poésie-Gallimard, 1942, 1948.

Ponge, F., Méthodes. Gallimard, 1961.

Ponge, F., Nouveau Recueil. Gallimard, 1967.

Ponge, F. \& Sollers, Ph., Entretiens de Francis Ponge avec Philippe Sollers. Gallimard/ Le Seuil, 1970.

Ponge, F., Pièces. Poésie, Gallimard, 1971.

Ponge, F., La Rage de l'expression. Poésie-Gallimard, 1976.

Ponge, F., L'Atelier contemporain. Gallimard, 1977. 